\title{
Cystolithotripsy Using the Holmium YAG Laser
}

\author{
Manabu Kawano, Ryoji Yasumoto, Takashi Tsujino, Kiyo Shindow, \\ Tamihiro Sakakura, Takuo Kono, Masazumi, Asakawa, Nobuyasu Nishisaka \\ and Taketoshi Kishimoto
}

Department of Urology, Osaka Municipal Juso Citizen's Hospital and Osaka City University Hospital, 2-37,Juso-higashi, Yodogawa-ku, Osaka, 532, Japan.

\begin{abstract}
Endoscopic laser cystolithotripsy was performed in 5 patients with bladder stones. The average stone size was $26 \times 18 \mathrm{~mm}$, and the average time for laser lithotripsy was 46 minutes. The stone composition was uric acid in 3, calcium phosphate in 2 and calcium oxalate in 1 patient.

Lithotripsy with the holmium YAG laser was successful in all cases. There were no complications during the procedure. In conclusion, we confirm the holmium YAG laser is ef fective and safe for cystolithotripsy.
\end{abstract}

Key words: laser cystolithotripsy, holmium YAG laser, bladder stone

\section{Introduction}

For fragmentation of bladder stones, endoscopic cystolithotripsy with electrohydraulic shock energy or crushing with Guyon forceps have been usually performed. Recently, laser lithotripsy has been developed as a new therapeutic modality, and is used for treatment of upper urinary urolithiasis. The present report describes clinical results of laser cystolithotripsy with the holmium YAG ( Ho: YAG) laser.

\section{Patients and Methods}

Endoscopic laser cystolithotripsy was performed in five patients with one or two bladder stones. The age ranged from 48 to 82 years old. The average stone size was $26 \mathrm{~mm}$ in long-length and $18 \mathrm{~mm}$ in short-length. Lithotripsy with the Ho:YAG laser was performed as follows; under spinal anesthesia, the patient was placed in lithotomy position. A $25 \mathrm{Fr}$. rigid renoscope was transurethrally inserted into the bladder. Under video monitoring, the tip of a 400 micron quartz fiber was placed in contact with the surface of the stone (Fig.1). At the first time, the energy was 


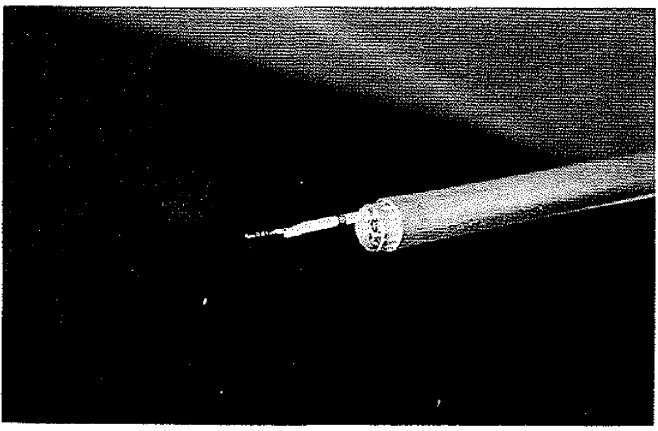

Fig.1. A. The tip of a 400 micron quartz fiber through ureteral catheter.

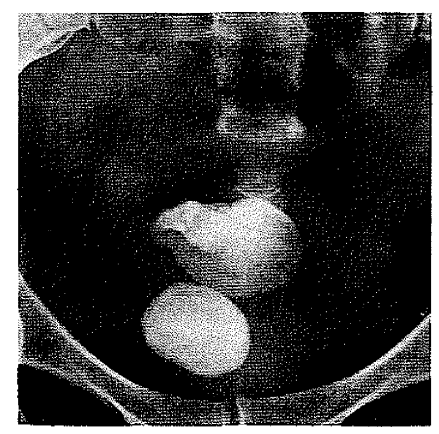

Fig.2. A. KUB before treatment shows larege bladder stones.

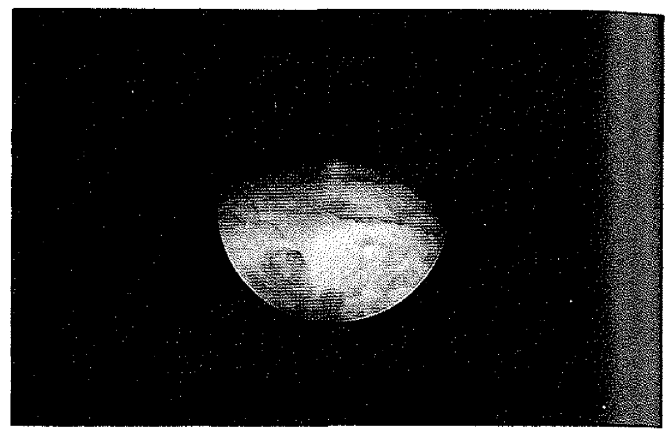

Fig.1. B. Laser cystolithotrispy. The stone was easily crushed.

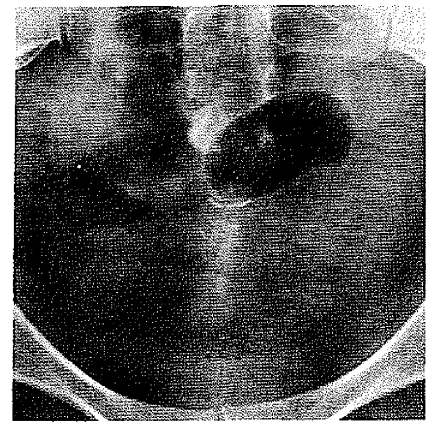

Fig.2. B. KUB after treatment. No stone was found.

set at 0.5 joules and delivered at 5 pulses per second. After making a few holes in the stone, the power of the laser was increased at the core of the stone. The power of the laser emission was set at more than 1.0 joules, and was gradually increased to 1.4 joules in case of insufficient fragmentation. This procedure was repeated until the stone was crushed. These fragments of the stones were removed by means of a stone evacuator or forceps (Fig.2).

\section{Results}

Fragmentation of a stone was achieved in all cases. The time for laser cystolithotripsy ranged from 20 minutes to 100 , with an average of 46 . The stone composition was uric acid in 3 , calcium phosphate in 2 and calcium oxalate in 1 . We could easily achieve whatever the composition might be (Table 1). Neither serious adverse reaction with laser beam, nor urethral bleeding in operation was observed during the procedure. 


\section{Discussion}

Extra corporeal shock wave lithotripsy and electric hydropressure lithotripsy have been used for treatment of urolithiasis. However, therapeutic limitation of those modalities is controversial. Recently laser lithotripsy has been developed for clinical use because it produces a small focal point of high power density enough to yield small stone fragments ${ }^{1-5)}$ (Table 2). There are many kinds of laser lithtriptors; e.g. dye laser, alexandrite laser, Nd:YAG, Ho:YAG, and so on . The sucessful rates of ureteral stone fragmentation were $67 \%$ by dye laser, $93 \%$ by alexandrite laser, $80 \%$ by Nd:YAG laser and $82 \%$ by Ho:YAG laser. On the other hand, the successful rates of the bladder stone fragmentation was $33 \%$ by alexandrite laser. It was lower compared to those of ureteral stone fragmentation. Then, we selected $\mathrm{Ho}: Y A G$; it is largely absorbed when it passes through water, hence it is safe because less energy reaches the stone surface. In adittion, its energy is as the same as the other lasers for fragmentation and has also a haemostatic cutting function ${ }^{6)}$. Jiang et al. reported favorable clinical results on fragmentation of ureteral stone ${ }^{7)}$. Matsuoka et al. also reported that fragmentation of ureteral calculi was easily achieved at lower power setting; 0.5 to 1.0 joules per pulse and 5 to 10 pulse per second $d^{5}$. However, fragmentation of a big stone such as bladder calculi has not been reported yet. In our experience, fragmentation

Table 1. Patients profile and clincal results.

\begin{tabular}{lccl}
\hline No - name - age & $\begin{array}{c}\text { stone size } \\
(\mathrm{xmm})\end{array}$ & $\begin{array}{c}\text { time (min.) for } \\
\text { laser lithotripsy }\end{array}$ & $\begin{array}{c}\text { stone } \\
\text { composition }\end{array}$ \\
\hline 1- YE - 82 & $29 \times 18$ & 25 & uric acid \\
2 - SH - 48 & $36 \times 23$ & 100 & Ca phosphate \\
& $47 \times 30$ & 50 & Ca phosphate \\
3 - HT - 71 & $23 \times 16$ & 50 & uric acid \\
$4-$ TY -78 & $15 \times 13$ & 30 & uric acid \\
$5-$ RY - 63 & $8 \times 5$ & 20 & Ca oxalate \\
average & $26 \times 18$ & 46 & \\
\hline
\end{tabular}

Table 2. Comparison of laser for lithotripsy.

\begin{tabular}{|c|c|c|c|}
\hline & \multirow[t]{2}{*}{$\begin{array}{c}\text { Wave length } \\
(\mathrm{nm})\end{array}$} & \multicolumn{2}{|c|}{$\begin{array}{c}\text { Successful } \\
\text { stone fragmentation }(\%)\end{array}$} \\
\hline & & kidney/ureter & bladder \\
\hline Dye laser & $504-594$ & 67 & $?$ \\
\hline Alexandrite laser & $750-755$ & 93 & 33 \\
\hline Neodymium YAG & 1064 & 80 & $?$ \\
\hline Holmium YAG & 2100 & 82 & $?$ \\
\hline
\end{tabular}


of a bladder stone was easy and safe by using the laser on setting 0.5-1.4 joules, 5-14 pulse per second. Although the stone whose component was uric acid colud be crushed with only $33 \%$ of the successful rate using alexandrite laser, all the bladder stone was easily crushed using the Ho:YAG laser. In conclusion, we confirm the Ho:YAG laser is effective and safe for cystolithotripsy.

\section{References}

1. Tsuboi,N., Horiuti,K., Oki,M., Sugizawa,Y., Honda,R., Hirose,H., Hasegawa,J., Yosida,K., Nisimura,T. and Akimoto,M. : Clinical treatment of urinary tract stones with alexandrite laser. Acta Urol. Jpn., 40, 101, 1994.

2. Maghraby,H., Knipper,A., Muschter,R. and Hofstetter,A.G. : Laser lithotripsy: Further experience with Nd: YAG laser. J. Endourology, 4:161, 1990.

3. Arai,T. : Ho:YAG laser treatment system. Igaku-no-Ayumi, 168, 813, 1994.

4. Furumoto, H.W.: A review of laser lithotripsy instrumentation (Part-II Lasers for lithotripsy): Jpn. J. Endourol. ESWL., 5:210, 1992.

5. Matsuoka,K., Shimada,A., Mihara,T., Nakanami,M., Noguchi,M. and Noda, S.: Holmium:YAG (Ho:YAG) laser for endoscopic lithotripsy., J. Urol. (abstract in AUA 89th anual meeting), 151: 249A, 1994.

6. Watson,G., Shroff,S. and Thomas,R.: "Holmium: YAG laser" multi functional use in urology. J. Urol. (abstract in AUA 89th anual meeting), 151: 372A, 1994.

7. Jiang, Z.X., Whitehurst,C. and King, T.A.: Fragmentation methods in laser lithotripsy, ibid., SPIE, 1421: 88, 1991. 